\title{
Isolated palmar located postherpetic Erythema multiforme: unique pathognomonic clinical presentation!
}

Ivanka Temelkova1, Georgi Tchernev ${ }^{1 *}$

${ }^{1}$ Onkoderma- Clinic for Dermatology, Venereology and Dermatologic Surgery, General Skobelev 26, 1606 Sofia.

Received: October 08, 2019; Accepted: October 08, 2019; Published: October 11, 2019

*Corresponding author: Prof Dr. Georgi Tchernev, Onkoderma-Clinic for Dermatology, Venereology and Dermatologic Surgery, General Skobelev 26, 1606 Sofia; E-mail: georgi_tchernev@yahoo.de

We present a 37-year-old woman complaining of recurrent herpes simplex infections in the genital area. Episodes of herpes recurrence have been observed within the last 2-3 years. The patient treated the viral infection in the past with acyclovir $3 \times 400 \mathrm{mg} /$ day with a temporary improvement. At the time of the clinical examination, the complaints were about the appearance of oval red lesions on the palms and fingers (Fig.
$1 \mathrm{a}-\mathrm{b})$ with a duration of several weeks. In the course of the dermatological examination, we detected disease progression as well as the presence of polymorphic rash units with the appearance of erythemo-edematous cockades-concentric circles with a peripheral erythematous ring and central clearing in the area of the palms and fingers (Fig. 1a-c). Based on a clear clinical picture and histological finding, a palmar form of erythema
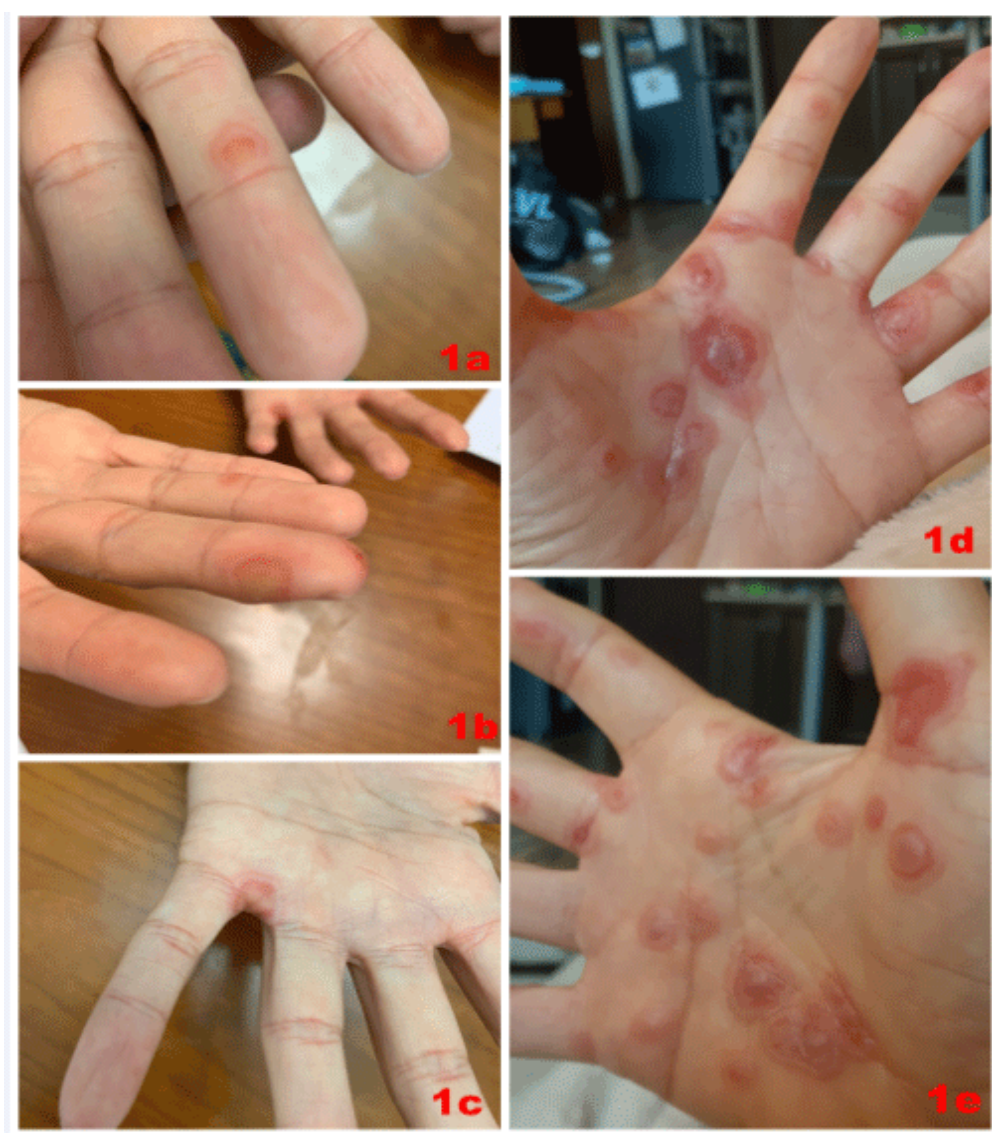

Figure. 1a-c: polymorphic rash units with the appearance of concentric circles with a peripheral erythematous ring and central clearing in the area of the palms and fingers. Photos 4 weeks before hospitalization.

Figure. 1d-e: erythema multiforme picture - clinical status after worsening of the condition. 
multiforme was diagnosed as a result of recurrent infection with herpes simplex virus in the genital area. There was no evidence of a general disorder as well as mucosal involvement within the erythema multiforme. Systemic therapy with methylprednisolone $60 \mathrm{mg}$ was started under a regimen initially followed by $40 \mathrm{mg}$ / day p.o. in reduction sheme for one month. Esomeprazole $40 \mathrm{mg}$ once daily for the duration of corticosteroid intake, as well as desloratidine $5 \mathrm{mg} /$ day, and topical administration of methylprednisolone aceponate cream $0.1 \%$ x 2 per day.

In outpatient treatment, prophylaxis for recurrent herpes infections with acyclovir $2 \times 400 \mathrm{mg}$ was initiated for a period of 6 months.

HSV infection is considered to be one of the major etiologic causes of acute or sequellar EM lesions [1]. Usually, the predisposing factors are unknown, with the condition being considered an immune-mediated reaction, which is more common in HSV-1 compared to HSV-2 in the context of herpes infection [2]. Although it is generally accepted that EM has a self-limited course of development in some cases timely adequate treatment of erythema multiforme remain a major challenge, especially within recurrent herpes-associated erythema multiforme (HAEM), as in the patient described by us $[2,3]$.

\section{References}

1. Hafsi W, and Badri T. Erythema Multiforme. StatPearls [Internet]. Treasure Island (FL): StatPearls Publishing; 2019, 2.

2. Magri F, Chello C, Pranteda G, and Pranteda G. Erythema multiforme: Differences between HSV-1 and HSV-2 and management of the disease-A case report and mini review. Dermatol Ther. 2019;32(3):e12847.doi: 10.1111/dth.12847. Epub 2019 Feb 10.

3. Lerch M, Mainetti C, Terziroli Beretta-Piccoli B, and Harr T. Current Perspectives on Erythema Multiforme. Clin Rev Allergy Immunol. 2018; 54(1):177-184. doi:10.1007/s12016-017-8667-7. 